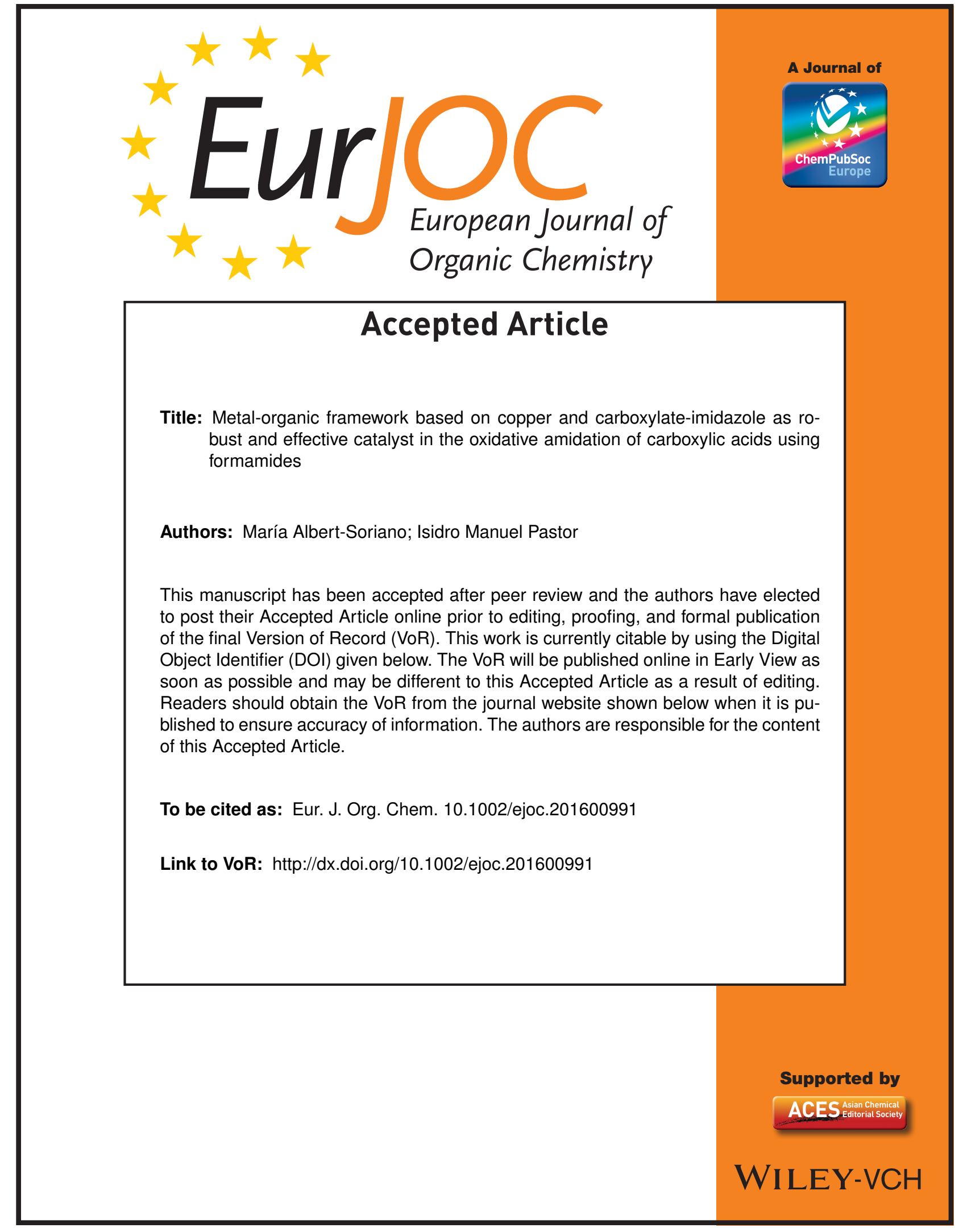




\title{
Metal-organic framework based on copper and carboxylate- imidazole as robust and effective catalyst in the oxidative amidation of carboxylic acids using formamides
}

\author{
María Albert-Soriano, ${ }^{[a]}$ and Isidro M. Pastor ${ }^{*[a]}$
}

\begin{abstract}
A metal-organic framework (MOF) based on copper and 1,3-bis(carboxymethyl)imidazole $\left[\mathrm{Cu}(\mathrm{bcmim})_{2}\right]$ has been prepared up to gram-scale, using a precipitation methodology at room temperature. The MOF-Cu(bcmim $)_{2}$ has proved to be a very efficient catalyst in the preparation of amides via an oxidative coupling between carboxylic acids and formamides in the presence of an oxidant, such as TBHP. The methodology for the preparation of amides has shown to be very robust regardless of the carboxylic acid, giving good conversions and selectivities. The heterogeneous catalyst has been recovered unaltered after the reaction, being easily separated from the reaction mixture and subsequently reactivated by suitable treatment. Moreover, the coupling reaction has been scaled up to gram-scale, being possible to prepare valuable products, such as fatty acid amides (i.e. 1palmitoylpiperidine).
\end{abstract}

\section{Introduction}

The imidazole derivatives bearing carboxylic moieties have been employed both as $\mathrm{N}$-heterocyclic carbene $(\mathrm{NHC})$ precursors and as ionic liquids (ILs), being applied to different catalytic processes. ${ }^{[1]}$ Recently, metal-organic frameworks (MOFs) have been prepared employing carboxy-functionalised imidazoles due to the excellent coordination ability of this type of substituents. Indeed, metal-organic frameworks with ligands based on carboxylate-imidazole salts (in zwitterion form) have been prepared in combination with various metals, such as strontium, ${ }^{[2]}$ cesium, ${ }^{[3]}$ cobalt, ${ }^{[4]}$ lanthanum, ${ }^{[5]}$ neodymium, ${ }^{[5]}$ copper $^{[6]}$ and manganese. ${ }^{[7]}$ Moreover, zwitterion carboxylateimidazoles have been treated with an acid giving their corresponding imidazolium salts, ${ }^{[8]}$ which have been also linked to metals in the preparation of MOFs. In particular, chloride and bromide salts have been utilised in combination with cobalt, ${ }^{[9]}$ zinc, ${ }^{[9,10]}$ calcium,${ }^{[3]}$ barium,${ }^{[3]}$ strontium, ${ }^{[3]}$ lead,${ }^{[11]}$ lanthanum, ${ }^{[12]}$ europium, ${ }^{[12]}$ praseodymium, ${ }^{[12]}$ bismuth $^{[13]}$ and copper ${ }^{[6]}$ for the synthesis of this type of structures.

The formation of carbon-heteroatom bonds is an essential tool for the preparation of chemical compounds of both academic

[a] M. Albert-Soriano, I. M. Pastor

Organic Chemistry Dpt. and Instituto de Síntesis Orgánica (ISO)

University of Alicante

Apdo. 99, 03080, Alicante (Spain)

E-mail: ipastor@ua.es

http://orcid.org/0000-0002-8271-0641

Supporting information for this article is given via a link at the end of the document. and industrial interest. ${ }^{[14]}$ Among the functional group transformations, the formation of amides ${ }^{[15]}$ is highly relevant due to their presence in several natural products and in many fine chemicals, agrochemicals, and pharmaceuticals. Indeed, a quarter of drugs in the market presents at least an amide bond. ${ }^{[16]}$ The condensation between an amine and a carboxylic acid is the most straightforward way of forming an amide, although it needs harsh reaction conditions. The use of an activating reagent, which transforms the carboxylic acid into a more reactive species, is an interesting strategy in order to soften the reaction conditions. In this sense, there is a plethora of coupling reagents for carrying out the amide formation under mild conditions in good yields, but it is necessary to use them in stoichiometric amounts. ${ }^{[17]}$ Alternative catalytic methods have been developed for direct amidation, although the reported protocols are still limited. ${ }^{[18]}$ Nowadays, oxidative couplings have emerged as a stimulating option to form $\mathrm{C}-\mathrm{N}$ bonds, ${ }^{[19]}$ among others. Thus, the formation of amides have been accomplished by coupling reactions between aldehydes or alcohols with amines or formamides. ${ }^{[20]}$ This type of coupling between aldehydes and amines has been catalysed by a copper based MOF. ${ }^{[21]}$ The use of less conventional precursors, such as carboxylic acids and formamides [mainly, dimethylformamide (DMF) and diethylformamide (DEF)], have been also coupled in the presence of homogeneous copper(II) salts [i.e. $\mathrm{Cu}(\mathrm{OAc})_{2},{ }^{[22]}$ $\left.\mathrm{CuCl}_{2},{ }^{[23]} \mathrm{Cu}(\mathrm{OTf})_{2},{ }^{[24]} \mathrm{Cu}\left(\mathrm{ClO}_{4}\right)_{2} \cdot 6 \mathrm{H}_{2} \mathrm{O}\right]^{[25]}$ and heterogeneous copper based nanoparticles [i.e. $\mathrm{CuO},{ }^{[26]} \mathrm{y}-\mathrm{Fe}_{2} \mathrm{O}_{3} @ \mathrm{SiO}_{2}-$ $\left.\mathrm{Cu}(\mathrm{acac})_{2}\right] \cdot{ }^{[27]}$ Hitherto, the oxidative coupling between a carboxylic acid and a formamide has not been described using metal-organic frameworks as catalysts (Scheme 1). Our group presents the first use of a MOF (based on copper), which is straightforwardly prepared under mild conditions, as effective catalyst in the synthesis of amides by oxidative coupling of carboxylic acids and formamides. This work was inspired by related $\mathrm{C}-\mathrm{H}$ activation of formamides, aldehydes and ethers with copper-MOFs. ${ }^{[28]}$ The $\mathrm{Cu}(\mathrm{II})$ centres, in the MOF based on copper and 1,3-bis(carboxymethyl)imidazole, are equivalent among them and with a square planar environment provided by four carboxylate oxygen donors. ${ }^{[6]}$ As a result, we consider that this geometry around the copper atom could allow this centre to be active as catalyst in oxidative coupling reactions. 


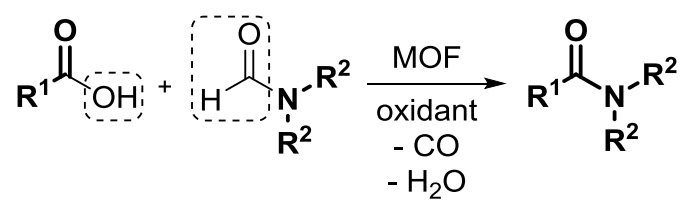

Scheme 1. Oxidative coupling of carboxylic acids and formamides considered in this work.

\section{Results and Discussion}

Cooper and 1,3-bis(carboxymethyl)imidazole based metalorganic framework. Our study started with the preparation of the ligand 1,3-bis(carboxymethyl)imidazole (bcmim, 1, see Supporting Information), as described in the literature, by reaction of glycine, glyoxal and formaldehyde (ratio 2:1:1). ${ }^{[1 e, 29]}$ Following, the metal-organic framework $\mathrm{Cu}(\mathrm{bcmim})_{2}$ was precipitated from an aqueous solution of biscarboxylate $\mathbf{1}$ and $\mathrm{Cu}(\mathrm{OAc})_{2}$ by adding methanol (Scheme 2). Accordingly, we obtained MOF-[Cu(bcmim $\left.)_{2}\right]$ as a blue solid following the procedure described by Abrahams, Robson and co-workers, ${ }^{[6]}$ albeit we scaled efficiently up the procedure to multi-gram scale (Scheme 2 and Supporting Information). The obtained blue solid was treated with methanol for several hours in order to purify and activate it. ${ }^{[30]}$

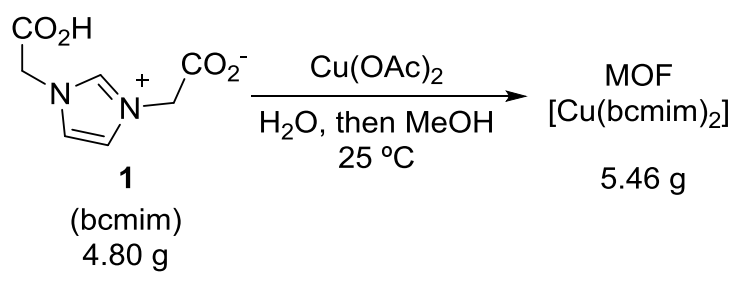

Scheme 2. Preparation of MOF-[Cu(bcmim $\left.)_{2}\right]$.

The prepared MOF-[Cu(bcmim $\left.)_{2}\right]$ was characterized by powder $X$-ray diffraction (PXRD), scanning electron microscopy (SEM), thermogravimetric analysis (TGA), elemental analysis, X-ray photoelectron spectroscopy (XPS) and Fourier transform infrared (FT-IR) spectrometry (Figures 1 and 2, and Supporting Information). Thus, the MOF presents crystallinity after the preparation and activation procedures, when compared with the simulated pattern ${ }^{[6]}$ (compare Figure 1a and Figure 1b). The SEM images of the synthesised $\mathrm{Cu}(\mathrm{bcmim})_{2}$ are shown in Figure 2. The solid formed takes spherical form (Figure 2a), although these patterns are formed by small slab-like crystals (Figure $2 b$ ). In fact, after the treatment with methanol (washing/activation process) the SEM image shows the lamellar morphology of the small crystals but without any arrangement (Figure 2c). The thermal stability of the MOF was measured by TG analysis: $\mathrm{Cu}(\mathrm{bcmim})_{2}$ started to decompose ca. $275^{\circ} \mathrm{C}$ and a significant loss of weight was observed around $290{ }^{\circ} \mathrm{C}$ (see Supporting Information), the material being decomposed. The XPS analysis confirmed the presence of copper(II) in the MOF (see Supporting Information).

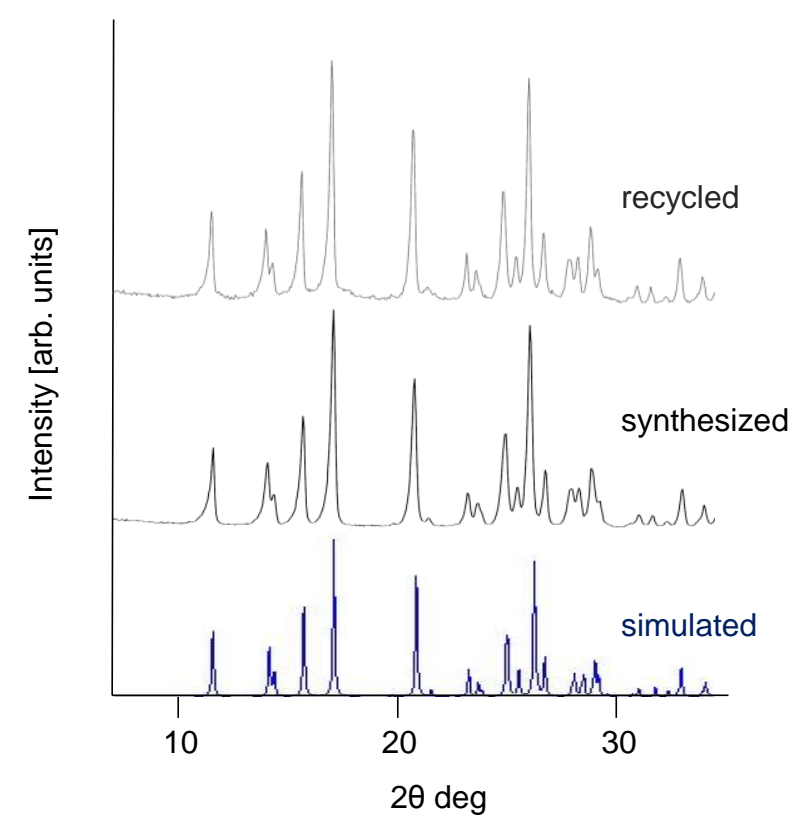

Figure 1. PXRD patterns of MOF-[Cu(bcmim) $)_{2}$ : (a) simulated, (b) synthesized and (c) recycled.

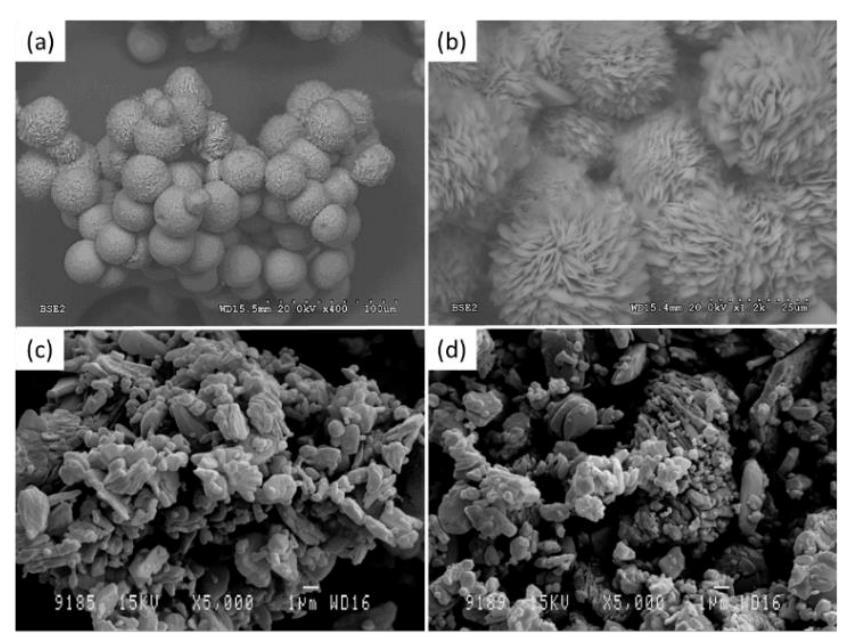

Figure 2. SEM of MOF-[Cu(bcmim)2]: (a) and (b) as precipitated using $\mathrm{Cu}(\mathrm{OAc}) 2$ and ligand $\mathbf{1}$ in a water/MeOH mixture, (c) after washing/activation with $\mathrm{MeOH}$ for several hours, (d) after recycling.

Catalytic activity in oxidative coupling between carboxylic acids and formamides: Optimisation. Following, we wondered about its catalytic activity in oxidative cross-coupling processes. Therefore, we were pleased to verify that the MOF-[Cu(bcmim $\left.)_{2}\right]$ catalyses the oxidative coupling between benzoic acid and 1formylpiperidine (2), in the presence of tert-butylhydroperoxide (TBHP), giving 1-benzoylpiperidine (3) with $48 \%$ conversion 
(>99\% selectivity, Table 1, entry 1 ). The absence of MOF gave no conversion and the starting materials were recovered, proving the need of the catalyst (Table 1, entry 2). Additionally, the reaction did not proceed without the oxidant (Table 1, entry 3). Preliminary experiments showed better conversions when the reaction is carried out with the flask open to the atmosphere (see Supporting Information), probably due to the need of releasing the pressure generated from gaseous by-products. Consequently, the study was continued performing the assays in open vessels. Furthermore, we proved temperature to be a crucial factor, thus a conversion of $41 \%$ was achieved after 2 days of reaction by lowering the temperature to $70 \stackrel{\circ}{ } \mathrm{C}$ (although the selectivity remained high, Table 1 , entry 4 , footnote b). In order to improve the conversion, we modified the amounts of catalyst and amide. The increase of catalyst amount to $20 \mathrm{~mol} \%$ produced practically no improvement in the conversion (Table 1, entry 5). In relation to the quantity of amide, there is an evident connection with the reaction progress. Indeed, employing 18 equivalents of amide gave a conversion of $77 \%$ whereas $33 \%$ of conversion was obtained by reducing it to 2 equivalents (Table 1 , compare entries 7 and 8 with entry 1 ).

Table 1. Oxidative coupling between benzoic acid and 1-formylpiperdine: Optimisation.

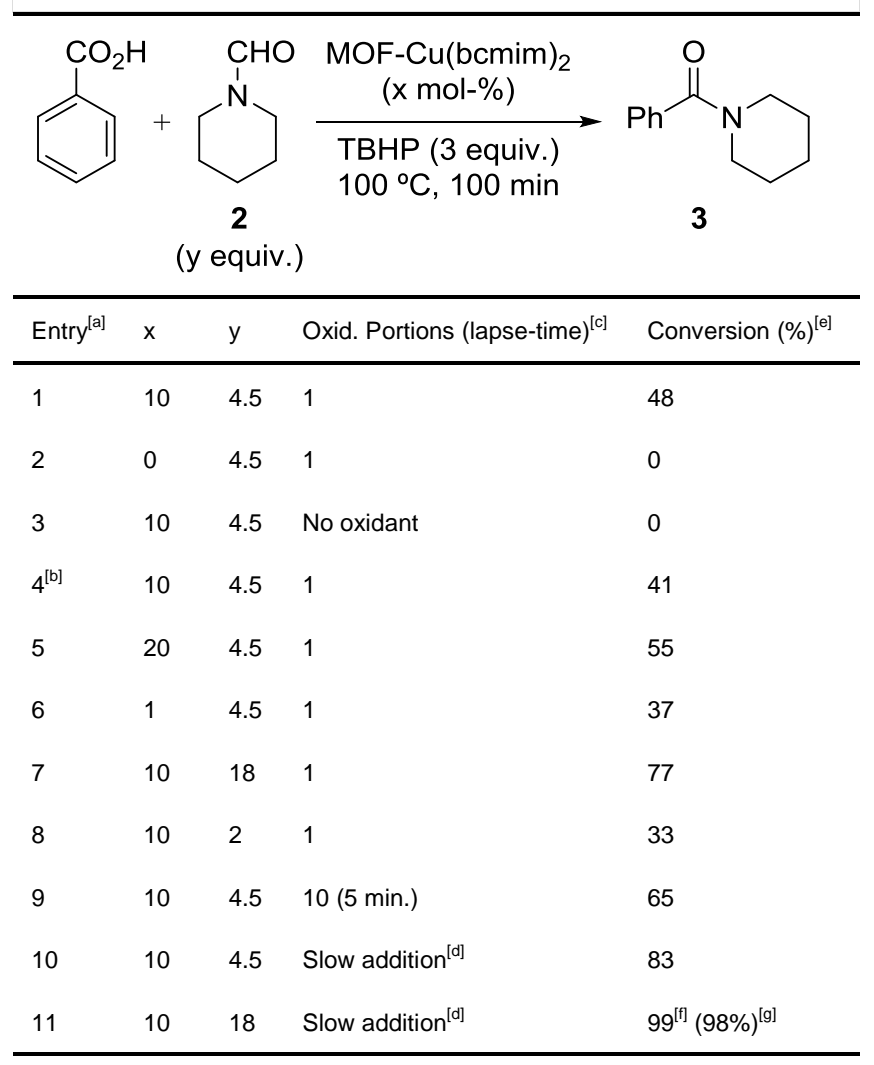

[a] Reaction conditions: benzoic acid ( $1 \mathrm{mmol}), 1$-formylpiperidine $(2,4.5$ or $18 \mathrm{mmol})$, TBHP (70\% water solution, $3 \mathrm{mmol}), \mathrm{Cu}(\mathrm{bcmim})_{2}(10 \mathrm{~mol} \%$ refer to copper, $43 \mathrm{mg}), 100^{\circ} \mathrm{C}, 100 \mathrm{~min}$. [b] Reaction performed at $70{ }^{\circ} \mathrm{C}$. [c] Lapse-time, when indicated, is the time between each oxidant portion added. [d] A syringe pump is used to add slowly the oxidant along $100 \mathrm{~min}$. [e] Conversion obtained by GC analysis. In all cases the selectivity of the reaction towards the formation of the amide product is $>99 \%$. [f] TON $=$ $9.9, \mathrm{TOF}=5.94 \mathrm{~h}^{-1}$. [g] In parentheses isolated yield of pure product.

At this point, we postulated the decomposition of the oxidant in the reaction media as a possible explanation for the incomplete conversion. Thus, an experiment was performed under the reaction conditions detailed in the entry 1 of Table 1 , but adding the whole amount of oxidant divided in 10 portions ( 1 portion every $5 \mathrm{~min}$ ). The conversion was slightly improved (Table 1, entry 9), what led us to think about slowing the addition along the reaction time. Therefore, the conversion was again improved (Table 1, entry 10), and in combination with a higher amount of amide resulted in complete conversion with an excellent selectivity (Table 1, entry 11). In the last experiment, product 3 was isolated as a pure compound with $98 \%$ yield, verifying the efficacy of the methodology.

Table 2. Oxidative coupling between benzoic acid and 1-formylpiperdine: Oxidant.

\begin{tabular}{|c|c|c|c|}
\hline $\mathrm{CO}_{2} \mathrm{H}$ & $\underbrace{\mathrm{CHO}}_{2}$ & $\begin{array}{c}\text { MOF-Cu(bcmim })_{2} \\
(10 \mathrm{~mol}-\%) \\
\begin{array}{c}\text { Oxidant }(1.5 \text { equiv. }) \\
100^{\circ} \mathrm{C}, 100 \mathrm{~min}\end{array}\end{array}$ & $\mathrm{Ph}_{\mathrm{N}}^{\mathrm{O}}$ \\
\hline Entry $^{[\mathrm{a}]}$ & Oxidant $^{[\mathrm{b}]}$ & & Conversion $(\%)^{[\mathrm{c}]}$ \\
\hline 1 & \multicolumn{2}{|c|}{ TBHP (water sol. 70\%) } & 70 \\
\hline 2 & \multicolumn{2}{|c|}{ TBHP (decane sol. 5.5 m) } & 46 \\
\hline 3 & \multicolumn{2}{|l|}{ DTBP } & 0 \\
\hline 4 & \multicolumn{2}{|l|}{ MCPBA } & 0 \\
\hline 5 & \multicolumn{2}{|l|}{ UHP } & 0 \\
\hline 6 & \multicolumn{2}{|c|}{$\mathrm{H}_{2} \mathrm{O}_{2}$ (water sol. 33\%) } & 8 \\
\hline $7^{[\mathrm{d}]}$ & \multicolumn{2}{|c|}{ TBHP (water sol. $70 \%$ ) } & 53 \\
\hline
\end{tabular}

[a] Reaction conditions: benzoic acid $(0.25 \mathrm{mmol}), 1$-formylpiperidine (18 equiv., $4.5 \mathrm{mmol}, 0.5 \mathrm{~mL} 0)$, oxidant (1.5 equiv., $0.38 \mathrm{mmol}), \mathrm{Cu}(\mathrm{bcmim})_{2}$ (10 mol-\% refer to $\mathrm{Cu}, 11 \mathrm{mg}$ ), $100 \stackrel{\circ}{\circ} \mathrm{C}, 100 \mathrm{~min}$. [b] Oxidant: tert-butylhydroperoxide (TBHP), di-tert-butylperoxide (DTBP, $m$-chloroperbenzoic acid (MCPBA), Urea- $\mathrm{H}_{2} \mathrm{O}_{2}$ complex (UHP), hydrogen peroxide $\left(\mathrm{H}_{2} \mathrm{O}_{2}\right)$. [c] Conversion obtained by $\mathrm{GC}$ analysis. [d] $10 \mathrm{~mol}-\%$ of $\mathrm{MOF}-\left[\mathrm{Cu}(\mathrm{BTC})_{2}\right]$ (HKUST-1, Basolite C-300) was employed as catalyst.

The use of TBHP as oxidant was initially stated based on similar catalytic procedures. ${ }^{[23-26]}$ However, we considered other oxidants in order to validate it (Table 2). Thus, TBHP (both water and decane solution), di-tert-butylperoxide (DTBP), metachloroperbenzoic acid (MCPBA), and hydrogen peroxide (as an aqueous solution and complexed with urea, UHP) were tested under the optimal conditions adding the oxidant at the beginning 
of the reaction (comparing with Table 1, entry 7), besides only 1.5 equivalents of oxidant were used to get margin for comparison. Only TBHP and $\mathrm{H}_{2} \mathrm{O}_{2}$ gave conversion (Table 2, entries 1,2 and 6), being better the use of aqueous solution of TBHP, as previously described.

For comparison, we performed the reaction with the commercially available MOF-[Cu(BTC) $)_{2}$ (HKUST-1; Basolite C-
300) under similar reaction conditions as described in Table 2 (compare entries 1 and 7, footnote [d]). The corresponding amide 3 was obtained with a conversion of $53 \%$, proving the higher activity of the prepared $\mathrm{Cu}(\mathrm{bcmim})_{2}$.

Table 3. Oxidative coupling of carboxylic acids with formamides. ${ }^{[a]}$

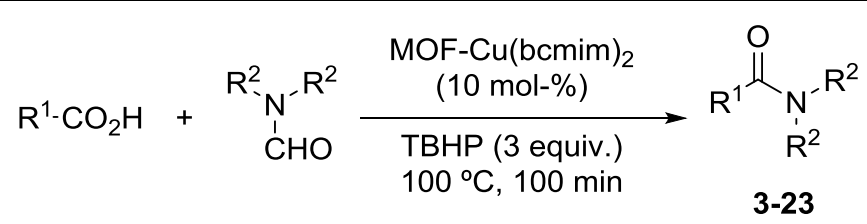<smiles>O=C(c1ccccc1)N1CCCCC1</smiles>

3, $98 \%(>99 \%)$<smiles>[X]c1ccc(C(=O)N2CCCCC2)cc1</smiles>

4, $X=1,86 \%(92 \%)$

5, $\mathrm{X}=\mathrm{Br}, 89 \%(>99 \%)$

6, $\mathrm{X}=\mathrm{Cl}, 93 \%(>99 \%)$<smiles>COc1ccc(C(=O)N2CCCCC2)cc1OC</smiles>

13, $95 \%(>99 \%)$

9, $\mathrm{R}=\mathrm{Me}, 66 \%(85 \%)$

10, $\mathrm{R}=\mathrm{CN}, 78 \%(>99 \%)$

11, $\mathrm{R}=\mathrm{OH}, 76 \%(>99 \%)$

12, $\mathrm{R}=\mathrm{NH}_{2}, 54 \%(95 \%)$<smiles>O=C(C1CCCCC1)N1CCCCC1</smiles>

$17,55 \%$ (>99\%)<smiles>O=C(c1ccccc1)N1CCOCC1</smiles>

20, 64\% $(91 \%)^{[\mathrm{d}]}$<smiles>O=C(NCC(=O)N1CCCCC1)c1ccccc1</smiles>

$18,95 \%(>99 \%)$<smiles>O=C(Cc1ccccc1)N1CCCC1</smiles>

21, $91 \%(>99 \%)$<smiles>O=C(c1ccccc1Cl)N1CCCCC1</smiles>

7, $92 \%(>99 \%)$<smiles>O=C(c1ccc2ccccc2c1)N1CCCCC1</smiles>

$14,92 \%(94 \%)$<smiles>O=C(c1cccc(Cl)c1)N1CCCCC1</smiles>

8, $89 \%(>99 \%)$<smiles>CCCCCCCCCCCCCCC(=O)N1CCCCC1</smiles>

19, $97 \%(98 \%)$ $\left[93 \%{ }^{[\mathrm{b}]}, 55 \%{ }^{[\mathrm{c}]}\right]$<smiles>O=C(NCc1ccccc1)N1CCCCC1</smiles>

$15, \mathrm{n}=1,80 \%(>99 \%)$

$16, \mathrm{n}=2,86 \%(>99 \%)$

[a] Reaction conditions: carboxylic acid $(1 \mathrm{mmol})$, formamide $(2 \mathrm{~mL}), \mathrm{Cu}(\mathrm{bcmim})_{2}(10 \mathrm{~mol} \% \mathrm{Cu}, 43 \mathrm{mg})$, TBHP $(70 \%$ water solution, $3 \mathrm{mmol}, 415 \mu \mathrm{L}), 100 \stackrel{\circ}{ } \mathrm{C}$ $100 \mathrm{~min}$. Yields are of isolated products. In parentheses are the conversions by GC analysis. Generally, the selectivities to the formation of the amide are $>99 \%$, being the only detected product. [b] Conversion using $5 \mathrm{~mol} \%$ of $\mathrm{Cu}(\mathrm{bcmim})_{2}$. [c] Conversion using $1 \mathrm{~mol} \%$ of $\mathrm{Cu}(\mathrm{bcmim})_{2}$. [d] Selectivity is ca. $80 \%$. [e] $6 \%$ of $\mathrm{N}$-ethyl-3,4-dimethoxybenzamide was obtained together with 22.

Catalytic activity in oxidative coupling between carboxylic acids and formamides: Scope, scale-up and recyclability.
The general versatility of this methodology was further evaluated for a variety of carboxylic acids under the optimised reaction 
conditions. Thus, carboxylic acids underwent oxidative coupling with 1-formylpiperidine catalysed by $\mathrm{Cu}(\mathrm{bcmim})_{2}(10 \mathrm{~mol} \% \mathrm{Cu})$ with the slow addition of TBHP as oxidant at $100{ }^{\circ} \mathrm{C}$ in an open vessel, and the results are shown in Table 3 . In general, excellent conversions with a high selectivity towards the formation of the corresponding amides 3-19 were observed, being the conversions higher than $92 \%$ in all the cases (except for 4-toluic acid). Regarding aromatic acids, both electron-rich and electron-deficient benzoic derivatives and 2-naphthoic acid formed neatly the corresponding amides 3-14 (Table 3), as the only observed product (excellent selectivity in all cases). Essentially, differences in the yield of pure product have to do with the isolation process. Notably, benzoic acids bearing halogen substituents (chloro, bromo and iodo), which can show reactivity in the presence of transition metal based catalysts, produced exclusively the expected amides 4-8 in yields from 86 to $93 \%$ (Table 3). Moreover, ortho-, meta- and parachlorobenzoylpiperidines (6-8, Table 3) were prepared without any significant difference. Remarkably, sensitive groups, such as hydroxyl $(-\mathrm{OH})$ and amino $\left(-\mathrm{NH}_{2}\right)$, were tolerated as substituents and the corresponding products 11 and 12 (Table 3) were exclusively produced.

Next, the study was extended to aliphatic carboxylic acids to explore the potential of our methodology. Gratifyingly, different acids were completely converted into the corresponding amides 15-19 (Table 3) with excellent conversions and selectivities. Among the substrates, a protected amino acid (i.e. $N$ benzoylglycine) was converted into the corresponding amide $\mathbf{1 8}$ (high conversion, and isolated yield of $95 \%$ ). In general, the smaller the acid the more difficult the purification of the amide derivative, so the cyclohexanecarboxamide derivative 17 was isolated with $55 \%$ yield. Actually, butyric acid coupled efficiently (97\% conversion) under the described reaction conditions, but 1 butyrylpiperidine could be only isolated with $5 \%$ yield. Interestingly, palmitic acid was transformed into the piperidine derivative 19, being obtained after purification in $97 \%$ yield. Fatty acid amides, such as 19, have been described as antituberculosis ${ }^{[31]}$ and anticancer agents. ${ }^{[32]}$ Thus, the protocol described here represents an interesting procedure for the preparation of this type of compounds. For that substrate, we proved that the amount of catalyst can be reduced to $5 \mathrm{~mol} \%$ with a slight reduction in the conversion (93\%, Table 3, footnote b). Lessening the catalyst to $1 \mathrm{~mol} \%$ produced a drop in the conversion to almost half ( $55 \%$, Table 3 , footnote c). Next, we proved that the reaction can be performed in gram scale without losing the effectiveness of the heterogeneous catalyst. Thus, 1.8 grams of palmitic acid was reacted during 140 minutes with 1 formylpiperidine in the presence of $10 \mathrm{~mol} \%$ of catalyst, being isolated 2.0 grams of 1-palmitoylpiperidine ( $90 \%$ yield, Scheme 3). The catalyst was removed by centrifugation, the excess of the amide was distilled off and the product was purified by filtration through a pad of silica gel (eluting with 1:1 ethyl acetate/hexanes mixture).

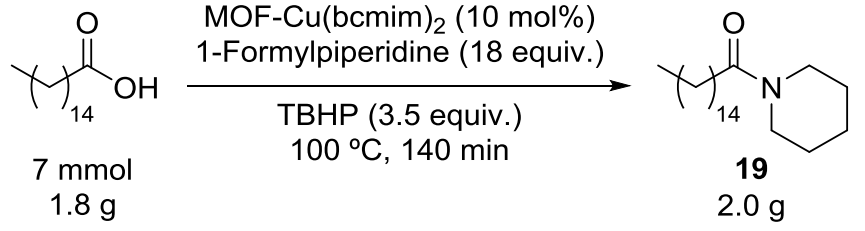

Scheme 3. Synthesis of 1-palmitoylpiperidine: gram scale.

The protocol described seems very robust regardless of the carboxylic acid (substituted aromatics, aliphatics), thus we coupled four different acids with other formamide derivatives in order to broaden its applicability. As previously observed, the catalyst performed correctly producing the amides 20-23 (Table 3 ), which could be isolated with yields in the range of $64-94 \%$. $\mathrm{N}$-Acylmorpholine derivatives present different bioactivities, ${ }^{[33]}$ so the formation of this type of compounds (such as 20) is of relevant interest. Additionally, the cyclic 1-formylpyrrolidine was coupled with phenylacetic acid giving product 21 exclusively. Moreover, the use of $\mathrm{N}, \mathrm{N}$-dialkyl formamides (such as diethyl or diisopropyl) gave smoothly the oxidative coupling process, and compounds $\mathbf{2 2}$ and $\mathbf{2 3}$ (Table 3) were isolated in excellent yields. Of the latter, product $\mathbf{2 3}$ is formed by an oxidative dealkylation process of the amide under the reaction conditions. ${ }^{[34]}$

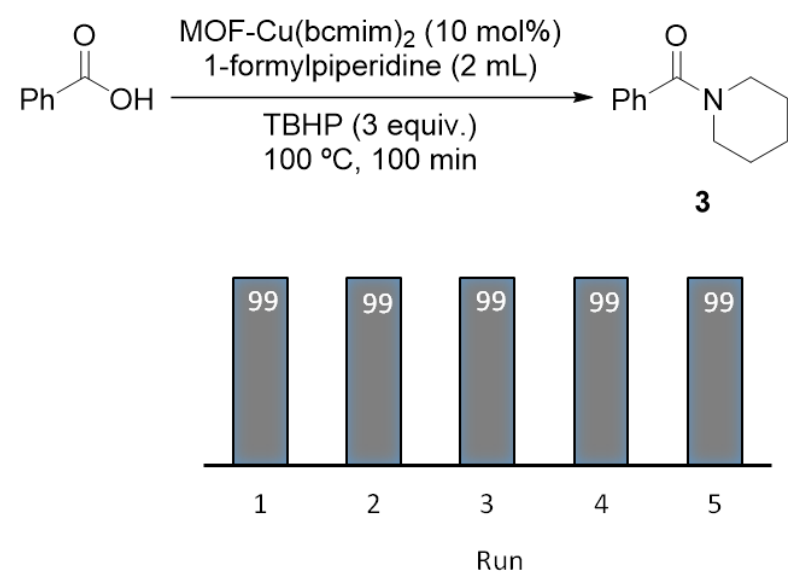

Scheme 4. MOF- $\left[\mathrm{Cu}(\mathrm{bcmim})_{2}\right]$ recyclability. Conversions by $\mathrm{GC}$ analysis. Accumulative $\mathrm{TON}=49.5$.

The recovery of the heterogeneous catalyst MOF-[Cu(bcmim $\left.)_{2}\right]$ and its recyclability are points at issue. Thus, a study of catalyst recyclability was carried out on the model reaction, i.e. the oxidative coupling between benzoic acid and 1-formylpiperidine using $10 \mathrm{~mol} \%$ of copper-MOF. After the reaction, the catalyst was easily separated from the reaction mixture by centrifugation. We observed that simple washing of the catalyst with organic solvents [i.e. stirring for $2 \mathrm{~h}$ in ethyl acetate (AcOEt), diethyl ether $\left(\mathrm{Et}_{2} \mathrm{O}\right)$, acetone or methanol $\left.(\mathrm{MeOH})\right]$, was not enough to 
recover completely the catalyst activity, being the conversions in the range of $60-80 \%$ in the second run. The partial deactivation could be due to by-products of the reaction, which remain attached to the catalyst. Indeed, a catalyst load (after the first run) was washed with $\mathrm{MeOH}$ for $2 \mathrm{~h}$ giving $62 \%$ conversion in the second run, and then it was treated during 2 weeks in $\mathrm{MeOH}$ recovering its activity ( $99 \%$ conversion in the third run). Finally, we found a shorter and straightforward protocol for recovering the catalyst activity. Truly, treating the catalyst with water for 1 minute and adding then $\mathrm{MeOH}$ allowed the recovery of the catalyst for the second run with the same activity (Scheme 4). It was even more interesting that the catalyst do not suffer any deactivation after 5 cycles (Scheme 4), following the same protocol of recycling. After the recycling experiment, we verified that the copper-MOF does not suffer any alteration during the oxidative coupling reaction. At first sight, the external appearance is similar to the fresh prepared and activated MOF (see Supporting Information). Definitely, the PXRD analysis proves the crystallinity of the recycled MOF to be intact (Figure 1c). The SEM image of the recycled $\mathrm{Cu}(\mathrm{bcmim})_{2}$ shows small crystals with lamellar morphology (Figure 2d), which are similar to the freshly prepared MOF after treatment with methanol (Figure 2c). The thermal stability (TG analysis) is identical to the MOF originally prepared (see Supporting Information). The XPS analysis after the recycling experiments showed the presence of copper(II) in the material (see Supporting Information). The recovered MOF presents the same elemental analysis (see Supporting Information) and similar percentage of copper (14.2 \% by ICP-OES, see Supporting Information), albeit the material $\mathrm{Cu}(\mathrm{bcmim})_{2}$ is very slitghly soluble in the amide (i.e. 51 ppm of copper detected by reaction media ICP analysis after separation of the MOF).

Oxidative coupling between carboxylic acids and formamides: Kinetic and mechanistic considerations. Based on our optimisation experiments, the amount of amide has proved to be important in the process. We confirmed the optimal amount (18 equiv.) of the amide, and we verified that higher amounts of amide did not have any positive effect in the reaction rate (see Supporting Information). Since structurally different acids provided good results in the amidation reaction, we wondered if the structure of the acid has any influence in the reaction rate. Therefore, we set up a competitive experiment with 4-cyanobenzoic acid and 4-methoxybenzoic acid. As can be seen in Figure 3, both acids reacted to form the corresponding amides 10 and 13, being the formation of both independently of each other. Indeed, both profiles are nearly parallel even when the concentration of 4-cyanobenzoic acid decreased sooner than 3,4-dimethoxybenzoic acid. The same behaviour was observed when 4-cyanobenzoic acid and 4-aminobenzoic acid were compared in a competitive experiment (see Supporting Information). This observation suggests that the carboxylic acid is not involved in the rate of the reaction, but the formamide. To confirm this proposition, the reaction profiles for different acids (i.e. benzoic acid, 4-cyanobenzoic acid and 4-aminobenzoic acid) were recorded showing a linear formation of the corresponding amides during the first 60 minutes of the reaction (see Supporting Information). Therefore, the concentration of the acid is linearly decreasing with time, confirming order zero with respect to the carboxylic acid.

Regarding the mechanism, oxidative coupling between acids and amides using copper catalysts have been proposed to proceed via radical intermediates. ${ }^{[25,27]}$ The use of a radical scavenger, such as TEMPO, inhibited the reaction between benzoic acid and 1-formylpiperidine, proving this pathway. Thus, we set an experiment following the protocol described in Table 3, and a sample was taken after 5 minutes, observing an $8 \%$ conversion. At this moment in time, TEMPO was added what produced the termination of the reaction (12\% of conversion after 50 minutes). Based on previous reports, ${ }^{[5]}$ the oxidant TBHP in the presence of the catalyst ( $\mathrm{Cu}$ based MOF) forms radical initiators (such as tert-butoxyl, tert-butylperoxyl, and hydroxyl) which generate carbamoyl radical A (Scheme 5). Then, intermediate $\mathbf{A}$ may lose $\mathrm{CO}$ to form aminyl radical $\mathbf{B},{ }^{[36]}$ which reacts directly with the acid to form the corresponding amide product [Scheme 5, Path (a)]. ${ }^{[35 a]}$ Other authors have proposed that intermediate $\mathbf{A}$ can react with the acid to form intermediate C, which produces the amide by releasing a $\mathrm{CO}_{2}$ molecule [Scheme 5, Path (b)]..$^{25,27]}$ Anyway, the reaction starts with the formation of radical intermediates from the formamide, which is the rate determining step as it was evidenced.

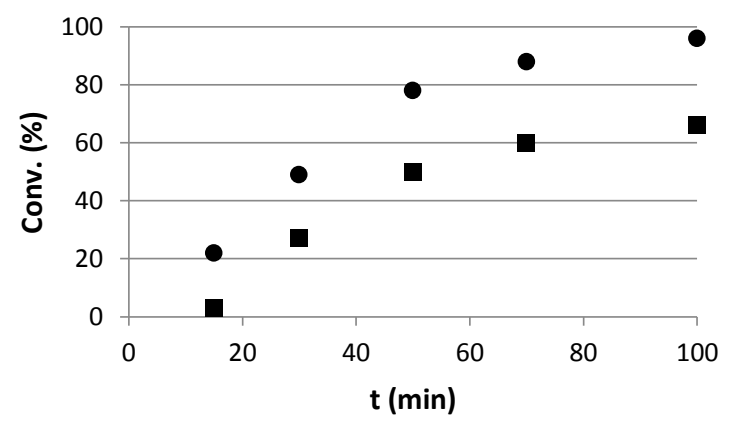

Figure 3. Reaction profile (competitive experiment) for two different carboxylic acids: $(\bullet)$ 4-cyanobenzoic acid and (घ) 3,4-dimethoxybenzoic acid. Reaction conditions: 4-cyanobenzoic acid (1 mmol), 3,4-dimethoxybenzoic acid (1 $\mathrm{mmol}), 1$-formylpiperidine $(2 \mathrm{~mL}), \mathrm{MOF}-\left[\mathrm{Cu}(\mathrm{bcmim})_{2}\right](10 \mathrm{~mol}-\%), 100{ }^{\circ} \mathrm{C}$, TBHP $(70 \%$ aqueous solution, $3 \mathrm{mmol})$. 


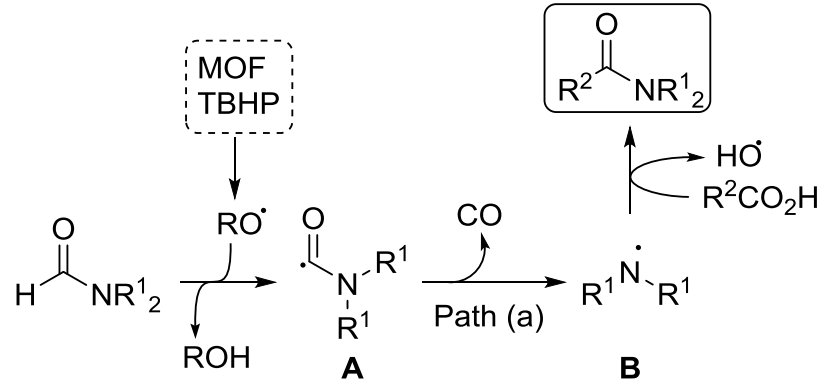

$\mathrm{R}^{2} \mathrm{CO}_{2} \mathrm{H} \backslash$ Path (b)

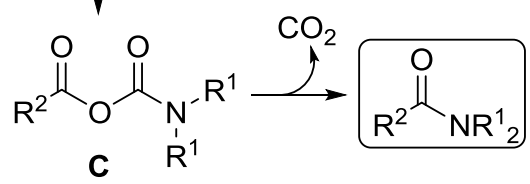

Scheme 5. Proposed reaction mechanism.

Study on the oxidative coupling with dimethylformamide. As commented in the introduction, the study of oxidative coupling of carboxylic acids with formamides, mediated by copper catalysts, have been generally performed with DMF. Thus, we wanted to test the catalytic activity of MOF-Cu(bcmim) $)_{2}$ with DMF, for comparison. The coupling reaction between 4-toluic acid and dimethylformamide in the presence of an oxidant was taken as model reaction (Table 4). The foreseen product $N, N, 4-$ trimethylbenzamide (24), previously described employing other copper catalysts, ${ }^{[22-27]}$ was obtained together with $\mathrm{N}, 4$ dimethylbenzamide (25) and $N$-formyl- $N$-methylaminomethyl 4toluate (26). The $\mathrm{N}$-acyloxymethylamides, such as compound $\mathbf{2 6}$ have been obtained in the oxidative coupling between phenylglyoxylic acid and DMF using tetrabutylammoninum iodide (TBAI) as catalyst, ${ }^{[37]}$ but they have never been observed by copper catalysts. Among the tested oxidants (TBHP, DTBP, $\mathrm{H}_{2} \mathrm{O}_{2}$, UHP, MCPBA and sodium percarbonate) only the TBHP, both in decane and aqueous solution, produced coupling products (Table 4, entries 1 and 2). The rest of the oxidants did not give almost any conversion even after 24 hours (see Supporting Information), as previously observed for 1formylpiperidine. Consequently, the following optimisation steps were performed using aqueous TBHP solution, since decane was employed as internal standard. Extending reaction time had no effect on the yield of products 24 and 25, although yield of product 26 was slightly lower (Table 4 , entry 3 ). An increase in the yield of all products was observed when the amount of oxidant was doubled, being the products in the same ratio (Table 4, entry 4).

Table 4. Oxidative coupling between 4-toluic acid and DMF: Optimisation.

\begin{tabular}{|c|c|c|c|c|c|c|}
\hline$[\mathrm{Ar}=$ & \multicolumn{2}{|c|}{ 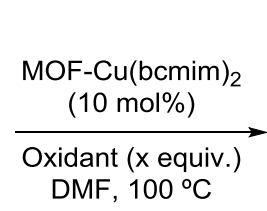 } & 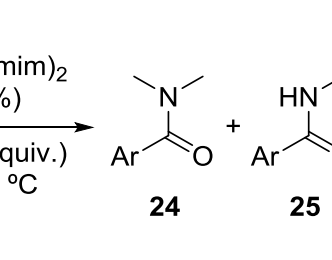 & \multicolumn{2}{|c|}{$+\underbrace{N_{2}^{-C r}}_{26}$} & \\
\hline \multirow[t]{2}{*}{ Entry ${ }^{[a]}$} & \multirow[t]{2}{*}{$x$} & \multirow[t]{2}{*}{$t(\min )$} & \multirow[t]{2}{*}{ Oxid. Portions (lapse-time) ${ }^{[c]}$} & \multicolumn{3}{|c|}{ Yield $(\%)^{[d]}$} \\
\hline & & & & 24 & 25 & 26 \\
\hline 1 & 1.6 & 90 & 1 & 14 & 4 & 28 \\
\hline $2^{[b]}$ & 1.6 & 90 & 1 & 14 & 4 & 26 \\
\hline 3 & 1.6 & 240 & 1 & 14 & 3 & 20 \\
\hline 4 & 3.2 & 270 & 1 & 30 & 10 & 35 \\
\hline 5 & 1.6 & 270 & $5(10 \mathrm{~min})$ & 25 & 6 & 40 \\
\hline 6 & 1.6 & 360 & $5(60 \mathrm{~min})$ & 31 & 5 & 47 \\
\hline 7 & 1.6 & 600 & 5 (120 min) & 29 & 4 & 34 \\
\hline 8 & 3.2 & 270 & 10 (10 min) & 30 & 5 & 43 \\
\hline
\end{tabular}

[a] Reaction conditions: 4-toluic acid $(0.25 \mathrm{mmol}), \mathrm{DMF}(0.5 \mathrm{~mL}, 25.8$ equiv.), TBHP (70\% water solution), $\mathrm{Cu}(\mathrm{bcmim})_{2}$ (10 mol\% refer to copper, $11 \mathrm{mg}$ ), $100 \stackrel{\circ}{\circ} \mathrm{C}$. [b] Reaction performed with TBHP (5.5 m in decane). [c] Lapse-time, when indicated, is the time between each oxidant portion added. [d] Yield obtained by GC analysis, using decane as internal standard.

Previously, we evidenced that the addition of the oxidant in different portions along the reaction time has influence in the yield of the reaction. Thus, the yield of the products was modified when the oxidant was added in 5 portions $(0.32$ equivalents each), being added a portion every 10 minutes (Table 4, entry 5). Best yield (47\%) for product 26 was obtained when the oxidant was added in 5 portions with 60 minutes lapsetime, albeit the yield of product $\mathbf{2 4}$ was also increased up to $31 \%$ (Table 4, entry 6). Finally, it was observed that neither enlarging the lapse-time nor the use of higher amount of oxidant had a positive effect (Table 4, entries 7 and 8).

Additional studies were performed varying the amount of DMF, and employing different solvents in combination with DMF (see Supporting Information for further details). The reaction did not work in polar protic solvents (i.e. methanol and water). The use of toluene or ethers, such as tetrahydrofuran (THF), dimethoxymethane (DMM), dimethoxyethane (DME) and tertbutyl methyl ether (TBME), gave similar ratio of compounds 24 and 26, but with lower yields. The rest of tested solvents (i.e. hexane, cyclohexane and acetonitrile) decreased drastically the yield of all products (see Supporting Information for further details). Undoubtedly, best results were obtained in the absence of any additional solvent, apart from DMF. 


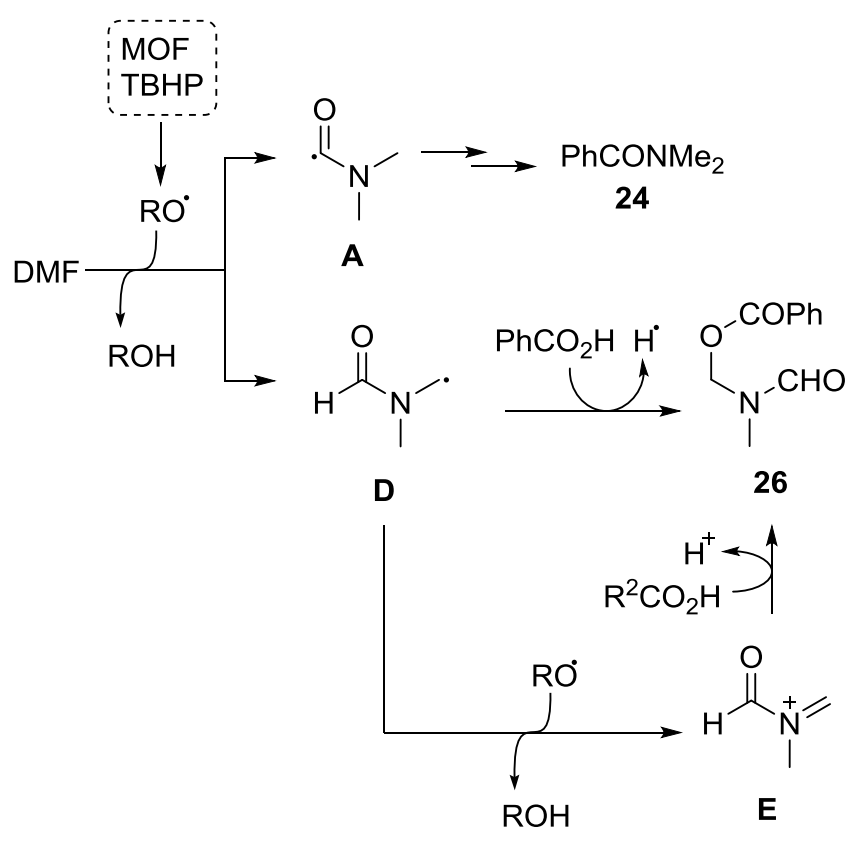

Scheme 6. Formation of different radical intermediates form DMF.

After testing different reaction conditions, a mixture of products was obtained in all tests, being the ratio of the major products $\mathbf{2 4}$ and 26 ranging from 1:1.4 to 1:2. Certainly, the MOF$\mathrm{Cu}(\mathrm{bcmim})_{2}$ has different catalytic activity than copper salts, which only produce the amide product $24 .^{[22-27]}$ Although, it has not been observed previously under copper catalysis, the formation of both radical intermediates $\mathbf{A}$ and $\mathbf{D}$ is possible $\left(\right.$ Scheme 6) ${ }^{[38]}$ and their formation is energetically comparable. ${ }^{[39]}$ Indeed, performing the oxidative coupling with $\mathrm{N}, \mathrm{N}$ dimethylacetamide (DMA), instead of DMF, produced exclusively the acyloxylation product 27 (Scheme 7), since the formation of intermediate $\mathbf{A}$ from DMA is not possible. Furthermore, the formation of a radical in $\alpha \mathrm{C}$ to the carbonyl is disfavoured, both kinetically and thermodynamically, compared with the formation of a radical nearby the nitrogen. ${ }^{[36,39]}$ Regarding the mechanism, product $\mathbf{2 4}$ can be generated from radical $\mathbf{A}$ as above mentioned in Scheme 5. On the other hand, intermediate $\mathbf{D}$, which is stabilised by the adjacent nitrogen, can react with the acid giving the acyloxylation product $\mathbf{2 6}$ (Scheme 6). ${ }^{[3]}$ Alternatively, the formation of an iminium intermediate $\mathbf{E}$, by a subsequent oxidation of $\mathbf{D}$, cannot be completely ruled out as possible pathway in the formation of $\mathbf{2 6}$ (Scheme 6). ${ }^{[40]}$ Finally, minority product $\mathbf{2 5}$ is formed by in situ oxidative demethylation process. ${ }^{[34,41]}$
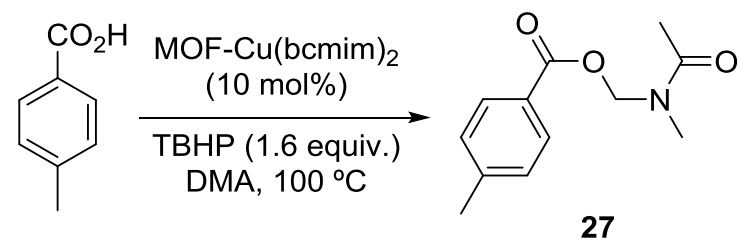

$(56 \%)$
Scheme 7. Oxidative coupling between 4-toluic acid and DMA.

\section{Conclusions}

In summary, we have optimised here the preparation in gram scale of a metal-organic framework $\left[\mathrm{Cu}(\mathrm{bcmim})_{2}\right]$ based on copper and 1,3-bis(carboxymethyl)imidazole. The MOF preparation is very easy (mild conditions) and with a quantitative yield. The MOF-Cu(bcmim $)_{2}$ is an efficient catalyst for the oxidative coupling reaction between carboxylic acids and formamides, being the first type of this heterogeneous catalyst described for this amidation reaction. The optimised protocol seems to be very robust regardless of the carboxylic acid, providing the corresponding amides in good conversions and selectivities. The oxidative coupling proceeds better in an opened-vessel and with the slow addition of the oxidant. Moreover, the amidation reaction can be performed in gram scale, as proved for the preparation of a fatty acid amide (i.e. 1palmitoylpiperidine). The MOF is easily recovered at the end of the reaction, and it has not suffered any modification in its structure. Therefore, the catalyst can be reactivated by proper treatment.

\section{Experimental Section}

General. All commercially available reagents and solvents were purchased (Acros, Aldrich, Fluka) and used without further purification. Melting points were determined using a Gallenkamp capillary melting point apparatus (model MPD 350 BM 2.5) and are uncorrected. ${ }^{1} \mathrm{H}-\mathrm{NMR}$ and ${ }^{13} \mathrm{C}$-NMR spectra were recorded at the technical service of the University of Alicante (SSTTI-UA), employing a Bruker AC-300 or a Bruker Advance-400. Chemical shifts $(\delta)$ are given in ppm and the coupling constants $(\mathcal{J})$ in $\mathrm{Hz}$. Low-resolution mass spectra (EI) were obtained at $70 \mathrm{eV}$ with an Agilent 5973 Network spectrometer, with fragment ions $\mathrm{m} / \mathrm{z}$ reported with relative intensities (\%) in parentheses. Low-resolution HPLC with electrospray ionization (HPLC-ESI) mass spectra were recorded at the technical service of the University of Alicante (SSTTI-UA), employing an Agilent 1100 series apparatus with the possibility of MS/MS. Infrared spectra were recorded with an FT-IR 4100 LE (JASCO, Pike Miracle ATR) spectrometer. Spectra were recorded from neat samples and results are given in $\mathrm{cm}^{-1}$. Analytical TLC was performed on Merck aluminium sheets with silica gel 60 F254, 0.2 $\mathrm{mm}$ thick. Silica gel $60(0.04-0.06 \mathrm{~mm})$ was employed for column chromatography. P/UV254 silica gel with $\mathrm{CaSO}_{4}$ supported on glass plates was employed for preparative TLC. The conversion of the reactions and purity of the products were determined by GC analysis using a Younglin 6100GC, equipped with a flame ionization detector and a Phenomenex ZB-5MS column (5\% PH-ME siloxane): $30 \mathrm{~m}$ (length), $0.25 \mathrm{~mm}$ (inner diameter) and $0.25 \mu \mathrm{m}$ (film). ICP-OES analysis were performed at the technical service of the University of Alicante (SSTTIUA) employing a Perkin Elmer Optima 4300 DV or Perkin Elmer 7300 DV apparatus. Powder DRX analysis were performed at the technical service of the University of Alicante (SSTTI-UA) employing a Bruker D8Advance apparatus with Göebel Mirror and X-ray generator KRISTALLOFLEX K 760-80F (Power: 3000 W, Voltage: 20-60 KV y Current: $5-80 \mathrm{~mA}){ }^{1}$ DRX pattern simulation was performed with the software Mercury 3.5.1 (Build RC5). Centrifugation was carried out with a Nahita Model 2610 apparatus (4000 rpm). TGA analysis were performed 
at the technical service of the University of Alicante (SSTTI-UA) employing a Mettler Toledo TGA/SDTA851e/SF/1100 apparatus.

General procedure for the synthesis of amides 3-23. The corresponding acid $(1 \mathrm{mmol})$ and MOF-[Cu(bcmim) 2$](10 \mathrm{~mol}-\%, 43 \mathrm{mg})$ were placed in a vessel, followed by the addition of the corresponding amide $(2 \mathrm{~mL})$. The mixture was stirred at $100{ }^{\circ} \mathrm{C}$ while TBHP $(70 \%$ in water, $3 \mathrm{mmol}, 415 \mu \mathrm{L}$ ) was added slowly over a period of 100 minutes employing an addition pump. The mixture was allowed to cool down to room temperature and it was filtered through a pad of silica, celite and $\mathrm{MgSO}_{4}$, eluting with ethyl acetate. Ethyl acetate was removed undr reduced pressure. The excess of starting amide was distilled off $\left(1 \times 10^{-4}\right.$ to $4 \times 10^{-4} \mathrm{mbar}, 55-90 \stackrel{\circ}{\circ} \mathrm{C}$ ). The corresponding products were obtained after purification by preparative TLC or column chromatography.

\section{Acknowledgements}

The Spanish Ministry (Ministerio de Economía y Competitividad, CTQ2015-66624-P) and the University of Alicante are gratefully acknowledged for financial support. M.A.S. thanks the Spanish Ministry for an Assistantship. We thank Dr. Paz Trillo for fruitful discussions.

Keywords: Metal-organic framework $\cdot$ Copper $•$ Carboxylimidazole $\cdot$ Amides $\bullet$ Oxidative coupling

[1] a) X. Li, W. Geng, J. Zhou, W. Luo, F. Wang, L. Wang and S. C. Tsang, New J. Chem. 2007, 31, 2088-2094; b) L. Han, H.-J. Choi, S.-J. Choi, B. Liu and D.-W. Park, Green Chem. 2011, 13, 1023-1028; c) X. Jin, X.-f. $\mathrm{Xu}$ and K. Zhao, Tetrahedron: Asymmetry 2012, 23, 1058-1067; d) S. Kirchhecker and D. Esposito, ACS Symp. Ser. 2014, 1186, 53-68; e) R. Martínez, I. M. Pastor and M. Yus, Synthesis 2014, 46, 2965-2975; f) A. Allegue, M. Albert-Soriano and I. M. Pastor, Appl. Organomet. Chem. 2015, 29, 524-532; g) M. Liu, F. Wang, L. Shi, L. Liang and J. Sun, RSC Adv. 2015, 5, 14277-14284; h) A. Singh, T. Raj and N. Singh, Catal. Lett. 2015, 145, 1606-1611.

[2] Z. Fei, T. J. Geldbach, D. Zhao, R. Scopelliti and P. J. Dyson, Inorg. Chem. 2005, 44, 5200-5202.

[3] Z. Fei, T. J. Geldbach, R. Scopelliti and P. J. Dyson, Inorg. Chem. 2006, 45, 6331-6337.

[4] X. F. Zhang, S. Gao, L. H. Huo and H. Zhao, Acta Crystallogr. Sect. E 2006, 62, m3359-m3361.

[5] X.-C. Chai, Y.-Q. Sun, R. Lei, Y.-P. Chen, S. Zhang, Y.-N. Cao and H.H. Zhang, Cryst. Growth Des. 2010, 10, 658-668.

[6] B. F. Abrahams, H. E. Maynard-Casely, R. Robson and K. F. White, CrystEngComm 2013, 15, 9729-9737.

[7] X. Wang, X.-B. Li, R.-H. Yan, Y.-Q. Wang and E.-Q. Gao, Dalton Trans. 2013, 42, 10000-10010.

[8] Z. Fei, D. Zhao, T. J. Geldbach, R. Scopelliti and P. J. Dyson, Chem. Eur. J. 2004, 10, 4886-4893.

[9] P. Farger, R. Guillot, F. Leroux, N. Parizel, M. Gallart, P. Gilliot, G. Rogez, E. Delahaye and P. Rabu, Eur. J. Inorg. Chem. 2015, 53425350.

[10] a) Z. Fei, D. Zhao, T. J. Geldbach, R. Scopelliti, P. J. Dyson, S. Antonijevic and G. Bodenhausen, Angew. Chem. Int. Ed. Engl. 2005, 44, 5720-5725; b) Z. Fei, W. H. Ang, T. J. Geldbach, R. Scopelliti and P. J. Dyson, Chem. Eur. J. 2006, 12, 4014-4020.

[11] X.-W. Wang, L. Han, T.-J. Cai, Y.-Q. Zheng, J.-Z. Chen and Q. Deng, Cryst. Growth Des. 2007, 7, 1027-1030.

[12] L. Han, S. Zhang, Y. Wang, X. Yan and X. Lu, Inorg. Chem. 2009, 48, 786-788.
[13] X.-C. Chai, H.-H. Zhang, S. Zhang, R. Lei, Y.-P. Chen, Y.-Q. Sun, R.-Q. Sun and Q.-Y. Yang, Chin. J. Struct. Chem. 2009, 28, 1343-1348.

[14] a) A. Dhakshinamoorthy, A. M. Asiri and H. Garcia, Chem. Soc. Rev. 2015, 44, 1922-1947; b) V. P. Mehta and B. Punji, RSC Adv. 2013, 3 11957-11986; c) R. M. De Figueiredo, J. M. Campagne and D. Prim in Metal-catalyzed C-heteroatom cross-coupling reactions, Eds.: J. Cossy and S. Arseniyadis), John Wiley \& Sons, Inc., 2012, pp. 77-109; d) G. Evano, N. Blanchard and M. Toumi, Chem. Rev. 2008, 108, 3054-3131.

[15] Y. R. Mahajan and S. M. Weinreb, Sci. Synth. 2005, 21, 17-25.

[16] A. K. Ghose, V. N. Viswanadhan and J. J. Wendoloski, J. Comb. Chem. 1999, 1, 55-68.

[17] a) E. Valeur and M. Bradley, Chem. Soc. Rev. 2009, 38, 606-631; b) A. El-Faham and F. Albericio, Chem. Rev. 2011, 111, 6557-6602; c) J. R. Dunetz, J. Magano and G. A. Weisenburger, Org. Process Res. Dev. 2016, 20, 140-177.

[18] a) H. Lundberg, F. Tinnis, N. Selander and H. Adolfsson, Chem. Soc. Rev. 2014, 43, 2714-2742; b) $\mathrm{H}$. Lundberg and $\mathrm{H}$. Adolfsson, ACS Catal. 2015, 5, 3271-3277.

[19] a) V. Ritleng, M. Henrion and M. J. Chetcuti, ACS Catal. 2016, 6, 890906; b) C. Liu, D. Liu and A. Lei, Acc. Chem. Res. 2014, 47, 3459 3470; c) M.-L. Louillat and F. W. Patureau, Chem. Soc. Rev. 2014, 43, 901-910; d) A. Biafora and F. W. Patureau, Synlett 2014, 25, 25252530; e) H. KIm and S. Chang, ACS Catal. 2016, 6, 2341-2351.

[20] a) S. Muthaiah, S. C. Ghosh, J.-E. Jee, C. Chen, J. Zhang and S. H. Hong, J. Org. Chem. 2010, 75, 3002-3006; b) R. Cadoni, A. Porcheddu, G. Giacomelli and L. De Luca, Org. Lett. 2012, 14, 5014-5017; c) S. Kegnaes, J. Mielby, U. V. Mentzel, T. Jensen, P. Fristrup and A Riisager, Chem. Commun. 2012, 48, 2427-2429; d) C. Zhang, X. Zong, L. Zhang and N. Jiao, Org. Lett. 2012, 14, 3280-3283; e) M. Pilo, A Porcheddu and L. De Luca, Org. Biomol. Chem. 2013, 11, 8241-8246 f) R. E. Rodriguez-Lugo, M. Trincado and H. Gruetzmacher, ChemCatChem 2013, 5, 1079-1083; g) S. Wang, J. Wang, R. Guo, G. Wang, S.-Y. Chen and X.-Q. Yu, Tetrahedron Lett. 2013, 54, 6233 6236; h) L. Zhang, W. Wang, A. Wang, Y. Cui, X. Yang, Y. Huang, X. Liu, W. Liu, J.-Y. Son, H. Oji and T. Zhang, Green Chem. 2013, 15, 2680-2684; i) E. Sindhuja, R. Ramesh, S. Balaji and Y. Liu, Organometallics 2014, 33, 4269-4278; j) A. K. Padala, N. Mupparapu, D. Singh, R. A. Vishwakarma and Q. N. Ahmed, Eur. J. Org. Chem. 2015, 3577-3586; k) A. M. Whittaker and V. M. Dong, Angew. Chem., Int. Ed. 2015, 54, 1312-1315; I) D. Saberi, S. Mansoori, E. Ghaderi and K. Niknam, Tetrahedron Lett. 2016, 57, 95-99; m) C. Bai, X. Yao and Y. Li, ACS Catal. 2015, 5, 884-891.

[21] T. Truong, G. H. Dang, N. V. Tran, N. T. Truong, D. T. Le and N. T. S. Phan, J. Mol. Catal. A: Chem. 2015, 409, 110-116.

[22] W. Ali, S. K. Rout, S. Guin, A. Modi, A. Banerjee and B. K. Patel, Adv. Synth. Catal. 2015, 357, 515-522.

[23] Y.-X. Xie, R.-J. Song, X.-H. Yang, J.-N. Xiang and J.-H. Li, Eur. J. Org. Chem. 2013, 5737-5742.

[24] H.-Q. Liu, J. Liu, Y.-H. Zhang, C.-D. Shao and J.-X. Yu, Chin. Chem Lett. 2015, 26, 11-14.

[25] P. S. Kumar, G. S. Kumar, R. A. Kumar, N. V. Reddy and K. Rajender Reddy, Eur. J. Org. Chem. 2013, 1218-1222.

[26] S. Priyadarshini, P. J. A. Joseph and M. L. Kantam, RSC Adv. 2013, 3 18283-18287.

[27] D. Saberi, S. Mahdudi, S. Cheraghi and A. Heydari, J. Organomet. Chem. 2014, 772-773, 222-228.

[28] I. Luz, A. Corma and F. X. Llabres i Xamena, Catal. Sci. Technol. 2014, 4, 1829-1836.

[29] O. Kühl and G. Palm, Tetrahedron: Asymmetry 2010, 21, 393-397.

[30] F. X. Llabres i Xamena and J. Gascon, Metal Organic Frameworks as Heterogeneous Catalysts, RSC Publishing, Cambridge, 2013.

[31] C. D. R. M. D'Oca, T. Coelho, T. G. Marinho, C. R. L. Hack, R. d. C Duarte, P. A. d. Silva and M. G. M. D'Oca, Bioorg. Med. Chem. Lett. 2010, 20, 5255-5257. 
[32] M. Shisui and M. linuma, Preparation of palmitic acid amides as anticancer agents, Japan Patent. JP2010275204A, 2010

[33] a) J. lley, R. Moreira and E. Rosa, J. Chem. Soc. Perkin Trans. 21991 563-570; b) J. Bartroli, E. Turmo, M. Alguero, E. Boncompte, M. L. Vericat, J. Garcia-Rafanell and J. Forn, J. Med. Chem. 1995, 38, 39183932; c) K. V. Clemons and D. A. Stevens, Antimicrob. Agents Chemother. 1997, 41, 200-203; d) D. A. Stevens and B. H. Aristizabal, Diagn. Micr. Infec. Dis. 1997, 29, 103-106; e) J. Bartroli, E. Turmo, M. Algueró, E. Boncompte, M. L. Vericat, L. Conte, J. Ramis, M. Merlos, J. García-Rafanell and J. Forn, J. Med. Chem. 1998, 41, 1855-1868; f) J. L. Hubbs, N. O. Fuller, W. F. Austin, R. Shen, S. P. Creaser, T. D. McKee, R. M. B. Loureiro, B. Tate, W. Xia, J. Ives and B. S. Bronk, J. Med. Chem. 2012, 55, 9270-9282; g) M. E. Kavanagh, M. R Doddareddy and M. Kassiou, Bioorg. Med. Chem. Lett. 2013, 23, 36903696.

[34] J. lley and R. Tolando, J. Chem. Soc. Perkin Trans. 2 2000, 2328-2336.
[35] a) H. Wang, L.-N. Guo and X.-H. Duan, Org. Biomol. Chem. 2013, 11 4573-4576; b) Z. Liu, J. Zhang, S. Chen, E. Shi, Y. Xu and X. Wan Angew. Chem. Int. Ed. 2012, 51, 3231-3235.

[36] J. Hioe, D. Sakic, V. Vrcek and H. Zipse, Org. Biomol. Chem. 2015, 13, 157-169.

[37] S. Zhang, L.-N. Guo, H. Wang and X.-H. Duan, Org. Biomol. Chem. 2013 11, 4308-4311.

[38] G. P. Gardini, F. Minisci, G. Palla, A. Arnone and R. Galli, Tetrahedron Lett. 1971, 12, 59-62.

[39] H. Q. Doan, A. C. Davis and J. S. Francisco, J. Phys. Chem. A 2010 114, 5342-5357.

[40] Z. Q. Lao, W. H. Zhong, Q. H. Lou, Z. J. Li and X. B. Meng, Org. Biomol. Chem. 2012, 10, 7869-7871.

[41] Q. Liao and C.-j. Xi, Chem. Res. Chin. Univ. 2009, 25, 861-865. 


\section{Entry for the Table of Contents}

\section{FULL PAPER}

Amide synthesis by oxidative coupling between carboxylic acids and formamides mediated by a metalorganic framework based on copper and in the presence of an oxidant.

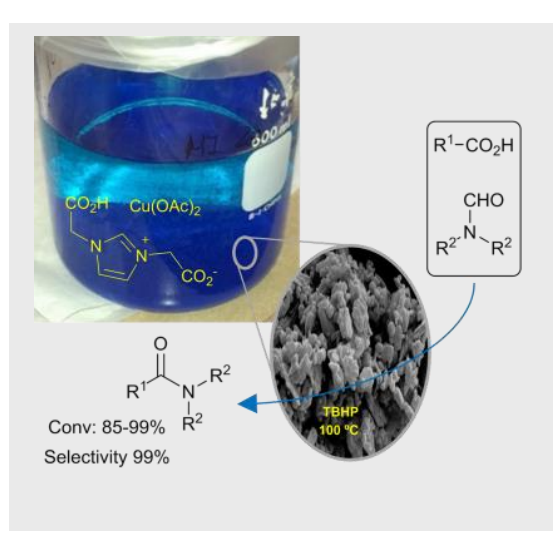

\section{Oxidative coupling}

María Albert-Soriano, Isidro M. Pastor

Page No. - Page No.

Metal-organic framework based on copper and carboxylate-imidazole as robust and effective catalyst in the oxidative amidation of carboxylic acids using formamides 